\title{
TRAZOS DUN GALEGUISTA E PROFESOR
}

\author{
ASPECTS OF A GALICIANIST AND TEACHER
}

\section{Ramón Villares Paz}

Agradezo á Real Academia Galega que me encomendase intervir neste acto do Día das Letras Galegas 2020, que está dedicado ao profesor, escritor e investigador Ricardo Carballo Calero, por máis que teña que ser celebrado en tempos marcados pola pandemia que está a invadir as nosas vidas desde o mes de marzo. Felizmente, a efeméride foi celebrada doutra maneira, en boa medida grazas a soportes distintos aos tradicionais e, nesta mesma adversidade, a figura de Carballo saíu triunfante.

$\mathrm{El}$, que era de natural algo tímido e amigo do traballo silandeiro, de rigor cartesiano e cortesía distante pero afectiva, vería con certa sorpresa esta gloria repentina que logrou pasados 110 anos do seu nacemento na cidade de Ferrol. Pero que a gloria chegue tarde non significa que sexa inmerecida, porque a súa personalidade, a súa extensa obra de escritor (poeta e narrador), de investigador e de profesor cunha fonda pegada nos milleiros de escolantes e lectores que tivo, son o mellor aval para construír a memoria de Carballo Calero. A súa figura representa cabalmente, nos seus logros e nas súas adversidades, o mellor da cultura galega do século vinte, a protagonizada por unha xeración excepcional, filla intelectual do grupo Nós e formada na eclosión creadora, cultural e política, representada polo Seminario de Estudos Galegos, a novísima Facultade de Letras da Universidade de Compostela e polo abrente político da II República: a "xeración do 36" como decote lle chamaría Luís Seoane, da mesma quinta que o noso homenaxeado.

Carballo Calero naceu na cidade de Ferrol en 1910 e finou en Compostela en 1990. Unha biografía de oitenta anos que cadra case perfectamente cos limites do que Eric J. Hobsbawm chamou o "curto século" vinte, acoutado por este historiador británico con dous acontecementos maiores: a Gran Guerra do 1914 e a creba do muro de Berlín, en 1989. A biografía de Carballo non dependeu destas marcas definidoras do pasado século, pero as súas vivencias cadran ben con algunhas liñas mestras do mesmo. El tivo a ilusión de mocidade e a confianza no futuro que tivo a sociedade europea de entreguerras, que se vía a si mesma como dona de seu que estaba a labrar un novo futuro; el viviu, como tantos outros, 
tempos de compromisos políticos e de extremos ideolóxicos, con guerras e xenocidios por medio; e el padeceu os tempos de chumbo da posguerra franquista, de resistencia calada, antes de encabezar o proxecto pedagóxico e cultural do Colexio de Fingoi ata que, quince anos despois, regresou ao lar materno da universidade onde se formara. Un regreso serodio pero que era todo un triunfo, fronte á súa biografía maltratada e fronte a outros potenciais concorrentes. El tivo a fortuna de colocar o incipit dunha cadeira coa que soñaran tantos galeguistas da súa quinta: os estudos de lingua e literatura galegas, brevemente desempeñados por Víctor Said Armesto na universidade de Madrid, pero nunca na universidade galega.

A biografía enteira de Carballo Calero, que felizmente goza de moitos cultivadores e admiradores, representa acaidamente a dun século decisivo para a cultura galega, canda a dos seus irmáns de pensamento e de acción anoados nos anos vinte e trinta. Os que lograron sobrevivir á desfeita do 36, fuxindo cara ao exilio ou mesmo sendo daqueles que se quedaron, marcáronse un obxectivo irrenunciable: que non se derramase a obra comezada, para devolvela, cando fose posible, ás novas xeracións. A un mestre de todos eles, Ramón Otero Pedrayo, non lle saía da pluma e da boca falar despois da guerra dos "novos", que desde os anos cincuenta, en Galicia e no exilio americano, comezaron a agromar como poetas nas Festas Minervais, como autores de relatos rompedores, como emprendedores de industria ou como universitarios con proxección exterior e unha común arela: reconstruír a cultura galega. Carballo foi un daqueles novos, aínda que da xeración inmediatamente anterior, a do 36. Pero todos xuntos foron os obreiros dunha cuadrilla de canteiros que labraron as pedras da cultura galega, antes e despois da censura da guerra civil, e xuntos ensinaron a que outros as labrasen, desde os anos cincuenta ata hoxe mesmo.

\section{1.}

Desde esta perspectiva, propóñome reparar en tres trazos da biografía de Carballo Calero nos que atopo un fío condutor que cose a súa obra pero tamén a súa executoria vital. Eses trazos teñen que ver cos espazos urbanos nos que el botou tempadas decisivas. En primeiro termo, Ferrol como cidade natal e de residencia na primeira posguerra; logo, Compostela como lugar de formación na mocidade e de retorno na madurez e senectude e, en terceiro pero non menos importante lugar, Lugo como un fecundo paréntese entre a "noite de pedra" dos primeiros anos de posguerra e unha peculiar "alba de groria" aberta coa experiencia singular, e mesmo única, do Colexio Fingoi, aquel centro situado fuori mura do "Lucus inspirado" como lle diría Otero Pedrayo, en evocación barresiana, nalgunha das epístolas ao seu discípulo e amigo cando estaba instalado na capital do alto Miño e comezaba a recuperar redes amicais e institucionais. 
O propio Carballo dixo nalgures que se sentía "ferrolán, lucense e compostelán", o que resulta totalmente certo. Pero se me encomendo a estas tres cidades non é só por lle facer xustiza ao noso autor. É para subliñar o que de ruptura tivo o mundo urbano na modernidade cultural e científica dunha Galicia que con demasiada frecuencia se asimila á sociedade rural, campesiña ou fidalga, da que a xeración Nós foi ben representativa, menos por orixes sociais do que por mitificación ideolóxica. A xeración de Carballo Calero tivo outras orixes e outras fasquías. Nunha das personaxes saída do maxín de Otero Pedrayo e que anda polo romance Devalar, que se chama Martiño Dumbría, está representada esta ruptura: el, como os seus amigos e amigas, era de extracción urbana ou vilega, de sentimento europeísta por galego, estudante que non paraba en pousadas "troianas" e que quería responder á pregunta esencial: "para que son bo?". Aquel Dumbría é expresión dunha figura colectiva que representa toda unha xeración, aquela á que pertenceu por dereito propio o profesor Carballo Calero e tantos outros Dumbrías que abandonaron agonías egotistas e decidiron educarse para ser útiles á súa Terra. Moitos destes novos Dumbrías, tan lonxe do modelo de Adrián Solovio, naceron na Galicia costeira, de Viveiro a Ferrol, de Negreira a Boiro, de Pontevedra a Ponteareas. Aqueles rapaces (unha sorte de millennials dos primeiros anos do século $\mathrm{XX}$ ) foron a espiña dorsal do Seminario de Estudos Galegos (SEG), do galeguismo republicano e autonomista, da guerra civil e do exilio exterior e interior.

Nacer na cidade de Ferrol, no tempo no que naceu Carballo Calero, tivo algo de alborada xeracional, que cadraba moi ben co tecido cultural e cos trazos ilustrados que a cidade desenvolveu desde a súa eclosión a mediados do século XVIII. Se algo caracteriza a esta cidade é unha racionalidade apolínea que moito se diferencia da fartura dionisíaca do continente rural galego no que está inserida. Aquela razón ilustrada fixo dalgúns dos seus moradores uns excelentes cultivadores da ciencia e dos saberes técnicos, con expertos como Jorge Juan ou Angel del Arenal, políticos liberais como Alonso y López, historiadores como Benito Vicetto, pensadoras e filántropas como Concepción Arenal e artistas como Felipe Bello Piñeiro ou o músico Pepito Arriola. Nunha cidade marcada polo arsenal militar e polos estaleiros navais, sobrancearon outros espazos de cultura, como lendarias academias, tal que a de Manuel Comellas, excelentes bibliotecas particulares, como a do comerciante Manuel Fernández Barreiro, un xornal de longa vida, El Correo Gallego, e unha sociabilidade urbana que gustaba da música e do teatro, como o emblemático Jofre, adornado coas trazas do arquitecto ferrolán Rodolfo Ucha. Cidade que volveu en si a principios do século XX grazas á recuperación da industria naval, encomendada á empresa inglesa Vickers, que trouxo de contado ("filispín", se podería dicir en argot ferrolán) gustos propios da illa de Albión que logo inzaron as rúas do barrio da Madalena e os tinglados dos estaleiros ferroláns. 
Naquel Ferrol, vello e novo, industrial e operario, militar e civil, no que se asentaron estirpes foráneas vascas, catalás e de ultra Mancha, foi onde naceu Ricardo Carballo Calero, que cadrou na súa infancia con outros nenos que chegarían a ser figuras destacadas no campo das letras e das artes. El-abondará citar os seus nomes para nos decatar de que o azar dun nacemento pode ser mudado pola compaña de que gozan os nados case nos mesmos lugares e nos mesmos tempos: Gonzalo Torrente Ballester (de Serantes), Santiago Montero Díaz, Ernesto Pérez Guerra (logo, Guerra da Cal) ou Xosé Rubia Barcia (de Mugardos), todos eles nados entre 1910 e 1914 e todos eles tocados fortemente polas musas. Canda eles, Carballo, no Ferrol natal e en moitas sazóns das súas fecundas vidas. Dous deles fixeron a guerra no bando franquista e tres no republicano con desigual futuro: Guerra e Rubia colleron camiño do exilio americano, asentándose como profesores en universidades norteamericanas, e un, o noso homenaxeado, condenado a botar uns anos en cárceres de Andalucía, ficou no interior, no bando dos vencidos. En todo caso, cinco nomes senlleiros para a historia de Ferrolterra.

En Ferrol cursou Carballo os seus estudos primarios e secundarios, en Ferrol pronunciou a súa primeira conferencia ("As ideas comunistas na República de Platón" nos locais do seu Centro Obreiro de Cultura) e á cidade departamental retornou despois de acabar os estudos universitarios, onde puxo casa de recén casado. De Ferrol saíu para facer as oposición a profesor de secundaria ("cursillista") en Madrid en 1936, como farían o seu conterráneo Rubia Barcia - que acabara os estudos de semíticas en Granada- e tantos outros. E a Ferrol retornou cinco anos despois de ter sido pai da familia in absentia e militar que fixo a guerra coa República na defensa de Madrid e logo, co grao de tenente de intendencia en campaña, no Exército do Sur (Valencia e Andalucía). Para acadar tal gradación fixo un rápido curso na Escola Popular de Guerra, na que ingresou "avalado por el Partido Galleguista”, segundo reza a súa ficha ministerial e confirman informes do galeguista Xohán Xosé Pla, que era coordinador do partido na zona republicana de Levante e Barcelona. Detido, xulgado e condenado a 12 anos de reclusión, chegou de novo a Ferrol, con dous anos de cárcere ao lombo e a marca de ser un depurado por razóns políticas e ideolóxicas. Estaba en réxime de "liberdade condicional" e debía sobrevivir como profesor de academias ou dando clases particulares, confirmando o pesimismo que tiña no cárcere militar de Xaén en febreiro de 1940: "hace tiempo que soy fiel perseguidor de la desventura", confesaba en carta dirixida ao seu amigo Francisco Fernández del Riego.

Naqueles tempos de chumbo, Carballo era, como lembra un dos seus discípulos, Fernando Pérez-Barreiro, "o máis interesante dos inhabilitados". Non era para menos, porque "as clases de Carballo eran moi especiais, serias e rigorosas", que segundo se di nas lembranzas deste avantaxado alumno eran todo menos 
escolásticas: falaba da "historia do pensamento", citaba nomes maiores da cultura europea como Hegel, Marx ou Spengler, e abría horizontes para escolantes afeitos a seguir docencias rutineiras. Discreto, "non falaba nunca da súa peripecia da guerra nin do seu pasado galeguista", pero nas súas accións ese pasado estaba ben presente, pois co seu amigo Francisco Usero convidou a Ramón Otero Pedrayo a dar unha conferencia en Ferrol, que tivo unha "fonda resonancia galeguista". Na carta de convite ao patriarca de Trasalba lembra Carballo que lle está a escribir "ao cabo de tantos anos" para retomar unha vella relación, non enferruxada polo paso do tempo; co seu rigor habitual, non exento de ironía, anúncialle que se compromete a "impoñer mesura apolínea ao dionisíaco temperamento do noso querido Usero". Non se sabe quen sería máis dionisíaco, se o presentador ou o orador.

A conferencia foi un éxito. $O$ alumno Pérez-Barreiro tomou notas que logo foron publicadas e a relación de Carballo con Otero xa non se interrompeu, porque a obra enteira de Otero, como escritor, historiador e mesmo orador, foi un referente constante para o traballo de creación e de investigación literaria de Carballo. A relación persoal e a admiración intelectual polo autor de Trasalba viñan dos tempos da República, pero reaparecen con toda a forza na sazón na que o contexto político e cultural vive unha pequena viraxe, a fins dos anos corenta, cando Otero xa viaxara a Arxentina e comezaba a falar en público, ás veces tamén en lingua galega. Pola súa banda, Carballo dedícase á creación poética ou narrativa e comeza a publicar libros ou textos de análise literaria. Un artigo de Carballo publicado, por suxestión de Piñeiro, na portuguesa revista Seara Nova, "Sobre a persoalidade de Ramón Otero Pedrayo" (1951), fai patente esta admiración, adiantando o que logo dirá do autor de Trasalba na Homaxe de 1958, a quen define, tomando emprestadas palabras do propio Otero, como "le prince d'Aquitaine à la tour abolie" ao que non lle resta máis que ser un "fiel amador dos crepúsculos" e salvador das ideas perdidas no naufraxio da infancia...

\section{2.}

Deixemos a Carballo ás portas do novo destino que lle esperaba en Lugo e volvamos á cidade que tanto o marcou, académica e politicamente: Santiago de Compostela, a onde chega no outono de 1926, con apenas quince anos pero con aires de home maduro, fateado de chapeu e de formas corteses. Non coñecía a cidade, pero desta primeira estadía en Compostela ficarán na alforxa de Carballo Calero algunhas alfaias que o marcarán de por vida: alén de lograr dúas licenciaturas universitarias - como adoito facían os bos estudantes da altura-, o mellor daqueles anos foi a creación dunha trama de amizades e de afectos con moitos Dumbrías que por Compostela andaban e que inmortalizou Seoane nalgún dos seus deseños, xuntando en amical faladoiro a Fernández del Riego, Cunqueiro, Ánxel Fole, Luís 
Manteiga, Sebastián González ou García Sabell, alén da que sería a súa dona de por vida, Ignacia Ramos. A segunda alfaia foi claramente a súa socialización no seo do galeguismo cultural e político, nun tempo no que a cidade de Compostela, coa universidade renovada, a creación do Seminario de Estudos Galegos, o asentamento do editor Ánxel Casal (que viña da Coruña) e do escenógrafo Camilo Díaz Baliño (que chegaba desde Ferrol) e, naturalmente, a explosión política dos anos da II República, fixo daquel grupo de escolleitos a verdadeira falanxe da primavera cultural e política de Galicia.

Un dos fundadores do SEG, Lois Tobío, lembra nas dúas Décadas de T.L. que na nova fornada de universitarios que arribaron a Compostela para seguir o curso 1926-1927 viñan uns poucos que aspiraban a educarse na vida cultural galeguista, alén de lograr ter un título universitario. Entre eles - lembra Tobío-, "chegaron de Ferrol dous rapaces que traian [na fronte] o sinal dos escolleitos: Ricardo Carballo Calero e Santiago Montero Díaz", este aínda algo máis novo. O rapaz que era Carballo é definido por Tobío como "serio, metódico e activo" que de contado entrou a traballar no SEG, a onde, segundo ten lembrado o propio Carballo, foi levado por outro dos fundadores: Ramón Martínez López. $\mathrm{O}$ compromiso co SEG daquel rapaz ferrolán foi inmediato e constante como organizador da súa gobernanza, como colaborador nas diversas xeiras realizadas polas "Terras" galegas, en Melide ou Deza e como membro da comisión que redactaría un dos documentos políticos máis relevantes do SEG, o Anteproxecto de Estatuto de Autonomía, en maio de 1931. Para Carballo, o SEG acabou por ser "un fogar, un casino" e, desde logo, un lugar para investigar ("facer papeletas") pero tamén un espazo de educación sentimental.

A formación política de Carballo á súa chegada a Compostela era moi fraca, polo menos no campo do galeguismo. Da cidade de Ferrol traía algunhas pingas de cultura galega, bebidas en Toxos e Frores ou en editoras como Céltiga, pero ningunha experiencia organizativa, xa que naquela cidade arraigara pouco o movemento das Irmandades e case desapareceu xa antes da chegada da ditadura de Primo de Rivera, inaugurando así un "eclipse do galeguismo" de case dez anos, en opinión de J. Beramendi. Foi en Compostela onde aqueles ferroláns "escolleitos" comezaron a militar politicamente, aínda que Carballo non tivese as derivas ou veleidades que caracterizaron a Santiago Montero. Diferenzas que non chegaron a romper as súas relacións persoais, como logo veremos.

Na universidade escolleu facer a carreira de Dereito, aínda que pouco a exercería, á que engadiu a licenciatura en Filosofía e Letras que cursou por libre, xa traballando como funcionario do Concello de Ferrol. Como escolante universitario, a figura de Carballo non pasou desapercibida. Alén das obrigas académicas, tivo un notable protagonismo no asociacionismo estudantil e no goberno da universidade. 
Como membro da Federación Universitaria Escolar (FUE), Carballo desempeñou tarefas de asesoría e organización da que tamén foi algún tempo o seu presidente, despois de Domingo García Sabell. Pero o máis importante daquela xeira vital de Carballo foi o seu protagonismo na tarefa de galeguización da institución universitaria e da súa democratización. No seu libro publicado en 1931 La fuerza pública en la universidad de Santiago está o esencial do pensamento dun rapaz de vinte anos que denuncia a violación do fuero universitario, apoia o novo reitor Alexandre Rodríguez Cadarso e introduce criterios de pragmatismo na xestión de folgas e outros conflitos universitarios.

A universidade compostelá estaba daquela acometendo unha profunda renovación que culminaría no curso 1930/1931, no que Carballo logra a súa licenciatura. A renovación principiara anos antes, cando comezou o proxecto de construír a chamada Residencia (universitaria) á beira do monte da Condesa, idea moi apoiada polas colectividades dos emigrantes en América. A novidade estaba en que se quería outro modelo de universidade, con novas facultades e unha concepción colexial da institución, creando a idea de campus universitario e rompendo coa tradición propia da Casa da Troia contra a que moito loitou toda aquela xeración, desde Carballo Calero - que, ironías do destino, morou en pousadas da rúa da Troia e arredores - a Luís Seoane ou Fernández del Riego, co amparo dun reitor sabio e culto, o médico Alejandro Rodríguez Cadarso, upado polos estudantes como "garantía contra o forasteirismo". Esa era unha das vertentes da galeguización universitaria, como sostén solemnemente o propio Carballo na parte final do seu discurso de inauguración oficial do curso académico de 1930/1931:

En esta hora jubilosa en que parece que los pueblos que integran el Estado español acusan con más relieve que nunca su afán de personalidad y su ansia de vida propia, la clase escolar gallega auténtica cree cumplir un deber ineludible solicitando por mi boca la galleguización de su Universidad.

Como acontece con frecuencia, o mellor dos tempos universitarios é o que se fai ou aprende fóra das súas aulas. No caso de Carballo, como no de moitos dos seus amigos daquela altura, foi o que sucedeu pero cunha novidade esencial: no canto de seren uns escolantes despreocupados e medio goliardescos -Seoane diría "troianos" -, converteron aqueles anos de estudo na ocasión para se integrar nunha laboría que tiña algúns mestres, os da Xeración Nós e das Irmandades da Fala, pero que carecían da forza da mocidade. Foi a combinación feliz daqueles tempos: unha universidade en renovación, unha galeguización da cultura, unha plataforma política que foi o Partido Galeguista e unha minoría consciente de escolleitos. En todas estas xeiras está presente o mozo Carballo Calero, primeiro 
como dirixente estudantil e, despois, como un dos mozos máis activos no proceso de reorganización do movemento das Irmandades que culmina coa fundación do Partido Galeguista en nadal de 1931, onde é elixido para formar parte do seu Consello directivo.

Un dos traballos máis sinalados do Carballo galeguista e republicano foi desempeñado en Ferrol desde finais de 1932, cando reorganiza o grupo galeguista da cidade e participa activamente nos debates internos do Partido Galeguista sobre a estratexia a seguir despois da chegada ao poder das dereitas a finais de 1933 . O "Grupo ferrolán do Partido", do que el sería presidente, comeza a se constituír en outubro de 1932, como amosan varias cartas que dirixe a membros do Partido como Fernández del Riego ou Paz-Andrade, aos que solicita apoio para enviar a Ferrol "algunha persoa de peso que poda vir", pensando en Lois Tobío e, en carta a Paz-Andrade, en Castelao, Suárez Picallo ou o propio Valentín. Que a sementeira galeguista en Ferrol estaba agromando confírmao un sorprendido Paz-Andrade que lle contesta a Carballo dicindo que "non agardabamos tanto os que de Ferrol tiñamos coñecimento antigo e certo" da situación. Non era para menos pois, en expresión do propio Carballo, o obxectivo dos galeguistas debería ser conquistar Ferrol para que deixe de ser "colonia castrense de Castela, Ulster e Gibraltar galego" (19/X/1932).

Como líder do galeguismo de Ferrol, Carballo Calero ten tamén unha actuación sobranceira na definición do Partido sobre bases democráticas que conduce a unha alianza co grupo de Manuel Azaña e que o leva a integrar as listas electorais da Fronte Popular, en febreiro de 1936, e mesmo a ser compromisario para a elección de Presidente da República en maio daquel ano. Naquela época na que se ventaban aires de bloqueo da política autonómica, a alianza coas esquerdas era unha garantía para o proceso autonomista. Un breve artigo de Carballo, "Xa somos ezquerda", publicado n'A Nosa Terra (febreiro de 1934), incidía nos acordos tomados na recente asemblea do Partido Galeguista celebrada en Ourense -á que el non asistiu - e adiantaba o que se volvería confirmar na asemblea de 1935. Aínda que esta esquerda se define no marco do galeguismo e non da política xeral, a posición de Carballo reflicte a estratexia que estaban a defender as camadas máis novas do Partido, logo asumidas por cabezaleiros como Castelao, Bóveda ou Suárez Picallo. Esta declaración mostra ben que a política galega cadraba cos rumbos da Europa dos anos trinta e que Carballo verbaliza claramente: "a radical, abismática diferenciación entre ezquerdas e dereitas, é hoxe un feito obsesionante, dramático, imposible de escamotear”. 


\section{3.}

Darei cabo a estes trazos sobre Carballo Calero, camiñando cara aos anos cincuenta, chegando canda el á terceira das cidades que marcou a súa biografía. Era Lugo unha cidade onde Carballo cursara por libre algunhas materias do bacharelato pero que anosou para sempre grazas ao seu casorio, pois alí moraba a familia da súa dona. Na cidade luguesa tiña xa algúns contactos políticos da época republicana, pois en 1932 Filgueira Valverde xa lle pide "nomes de rapaces galeguistas da provincia de Lugo" para seren contactados e á cidade de Lugo ía de cando en vez nos anos corenta desde a súa residencia de Ferrol. Como director do Colexio Fingoi botou quince anos de vida en Lugo, cidade que Carballo recordaría na conferencia pronunciada en 1974 no Centro Galego de Bos Aires, como unha cidade-acrópole recollida entre murallas, silandeira e moi apegada ao "terrón labrego". Alí pasaría a maior parte do tempo no propio Colexio, con saídas intermitentes aos faladoiros do Méndez Núñez ou visitas a Trasalba, Compostela e á Real Academia Galega, onde ingresa no ano 1958.

A instalación profesional na cidade das murallas ten lugar cando o enxeñeiro Antonio Fernández López, primoxénito do coñecido emprendedor lugués Antón de Marcos, decide abrir un centro educativo que formase con novos criterios pedagóxicos a rapaces da cidade: un "colexio experimental", en palabras do propio Carballo. Foi un proceso lento, que o propio Carballo viña acariñando desde anos antes. Como lle conta ao seu amigo Fernández del Riego, "sobre mi colocación en el Colegio de [Antonio] Fernández, vengo haciendo gestiones hace varios años" a través dos irmáns Emilio e Álvaro Gil Varela, aos que encontraba nas súas visitas vacacionais en Lugo. A confidencia feita a del Riego era polo mes de outubro de 1949. Aos poucos meses chegaría a confirmación de que fora o escollido.

A chamada de Fingoi cadraba coa situación persoal de Carballo pero tamén cos aires galeguistas que rodean aquel proxecto, pois galeguista é Antonio Fernández e o seu colaborador Álvaro Gil e galeguista é o arquitecto Gómez Román, que traza e dirixe a construción do edificio. E galeguista continuaba a ser Carballo Calero cando Antonio Fernández lle solicita, en xullo de 1950, que "se encargue de ir estudiando la organización del mismo [Colexio] para el próximo curso", proposta que Carballo acepta decontado. El non vai a cegas a Lugo, aínda que non sexa consciente do traballo que lle esperaba -"xornadas de traballo de once horas diarias", diríalle a Piñeiro-, pero con traballo e todo, Fingoi acabou por ser esencial na súa biografía de profesor e, sobre todo, de investigador e de resistente cultural asociado ao grupo Galaxia. Do ostracismo de Ferrol pasou a ser un daqueles "herois calados" que Luís Seoane encontra cando chega desde Bos Aires, en 1960, para conectar coa resistencia interior de tradición galeguista e republicana. Entre aqueles heroes, Seoane designa expresamente a Carballo Calero, a quen 
visita no Colexio Fingoi. Cheo de saudades, escríbelle ao pouco de retornar a Bos Aires para dicirlle que "fuches a primeira persoa amiga de sempre que eu vin en Galicia e si denantes tiña por ti amistade e admiración, unha e outra renováronse nos dous dias que pasei en Lugo", para acabar con un "non sei cando voltaremos" (14/IX/1960). Non tardarían moito en se volver a ver.

Da estadía de Carballo en Fingoi ficaron fondas pegadas nos estudantes, de ambos os sexos, que por alí pasaron e nos seus compañeiros de profesorado. Pero talvez o máis relevante para Carballo foi que este traslado a Lugo coincidiu coa fundación da Editorial Galaxia e a aposta dos galeguistas do interior polo "rexurdimento cultural”, no que Carballo, a xuízo de Piñeiro de decembro de 1949, "volverá ocupar o posto que lle corresponde" (carta de Piñeiro a Del Riego, 23/XII/1949). A obra de investigación que fixo Carballo nos tempos de Fingoi, malia as moitas horas que debía gastar en tarefas máis de xestión que de docencia, consolidou a súa biografía intelectual. Algunha das obras publicadas daquela ou máis adiante, de poesía e de narrativa, como A xente da Barreira, premio Bibliófilos Gallegos de 1950, xa estaban escritas antes de se asentar en Lugo. Pero en Fingoi escribe a Historia da literatura galega contemporánea, libro que alén dos seus textos de creación anteriores e posteriores, consagraría o autor na república das letras galegas.

Un fito importante na biografía intelectual de Carballo foi o de conseguir o título de doutor, que logrou coa tese Aportaciones a la literatura gallega contemporánea dirixida formalmente polo seu amigo ferrolán Santiago Montero Díaz en decembro de 1954. Tivo un tribunal de prestixio, presidido polo decano Francisco Javier Sánchez Cantón (que pediu "meterse no tribunal”) e con Dámaso Alonso de gran figura, que lle promete (e cumpre) editar o texto na editorial Gredos. De como correu aquela sesión académica, e das observacións algo "sibilinas" (en expresión de Carballo) de Sánchez Cantón "encol de Castelao e [de] Otero", dálle conta aos poucos días a Ramón Piñeiro (carta do 16/XII/1954). Debido a esta obra Carballo vaise convertendo no mellor experto sobre historia literaria galega, apadriñado polo grupo Galaxia. O gran proxecto da Historia da literatura, deseñado formalmente en 1956, está moi ben contado no epistolario cruzado de Carballo con Fernández del Riego e con Ramón Piñeiro, que fixeron de bibliotecarios amadores na procura de libros e folletos que o autor necesitaba para escribir o libro e para endereitar unha materia que tiña poucos e desatinados cultivadores naquela altura, segundo confesión propia.

\section{4.}

Unha brevísima coda para dar cabo a estes trazos biográficos do noso autor. A condición "experimental" do Colexio Fingoi, marcada por Carballo Calero, permite dicir que foi algo máis do que un colexio convencional que, de coidar as tarefas 
dun centro de ensino, foi evoluindo cara a unha educación integral, con actividades extraescolares, especialmente teatrais e musicais, excursións e contacto coa natureza, afeccións que Carballo partillaba con Antonio Fernández. Ademais, o seu mecenas concedía bolsas de estudo a profesores e antigos estudantes e sufragou todo un Centro de Estudos do que saíron libros de etnografía e investigacións sobre a literatura medieval galega. A existencia da Granxa de Barreiros en Ortoá (Sarria), tamén debida á familia Fernández, facilitaba esta permeabilidade entre experimentación e estudo regulado, de modo que se pode dicir que Fingoi foi en Galicia, desde os anos cincuenta, un oasis de "institucionismo" ao modo da Institución Libre de Enseñanza de Giner de los Ríos e dos seus discípulos. Como aconteceu cos mellores centros inspirados pola ILE, tamén os escolantes de Fingoi saíron positivamente marcados por aquela experiencia dun ensino de calidade, distinto, pensado sobre todo para educar e non como un rito de paso na biografía de cadaquén.

En 1965 acontece un novo cambio de cidade e mesmo de ocupación para Carballo Calero, que lle permite retornar por segunda vez a Compostela. A universidade adoptara o acordo de introducir as disciplinas de lingua e literatura galegas na acabada de crear Sección de Lenguas Románicas. O que daquela era decano da facultade, Abelardo Moralejo, chamou ao seu vello coñecido dos anos trinta para encomendarlle aquela tarefa. Malia as dificultades iniciais, materiais e tamén familiares, a decisión de Carballo Calero foi inmediata: aceptar o traslado a Compostela, onde acadaría a condición de catedrático da materia no ano 1972, á mesma idade na que o seu mestre Otero Pedrayo chegara á de xeografía, vinte e tantos anos antes. Con esta chamada tivo a oportunidade de volver ás rúas que "moito tripei" nos anos de escolante universitario. Quen daquela retornaba a Compostela era unha persoa algo diferente da que a abandonara en 1932 no que se refire á non militancia política partidista, pero era a mesma no rigor intelectual, no compromiso coa lingua e a cultura galegas e na convicción de que, se en 1932 Ferrol debía ser rescatado da condición de "colonia de Castela", algo semellante había que facer con Galicia na conxuntura do tardofranquismo e da transición á democracia e á autonomía. Naquel percurso biográfico padeceu tamén desabores e rupturas con vellas amizades e asistiu a polémicas moi destemperadas. Pero a imaxe máis sólida que fica de Carballo Calero é, empregando de novo palabras certas de Lois Tobío, a dun "mestre da nosa cultura non só no eido da filoloxía, en que sobranceaba, senón tamén como poeta, novelista, historiador e crítico". Deste modo era visto polos seus coetáneos e así penso que o debemos ollar no día de hoxe.

\section{Dixen.}

